\section{Allergy $_{\mathrm{and}}$ Immunology}

Int Arch Allergy Immunol 2013;162:272

DOI: $10.1159 / 000351668$
Published online: October 17, 2013

\title{
Associate Editor Massimo Triggiani
}

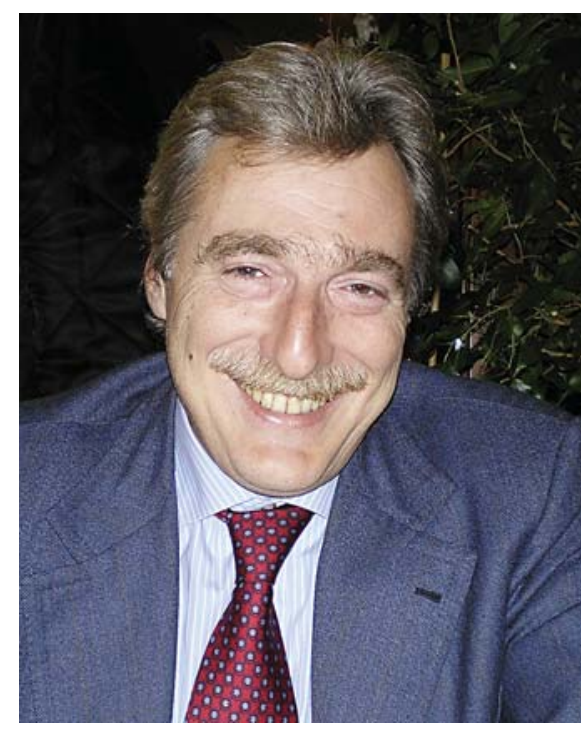

Massimo Triggiani, Salerno.
Dr. Massimo Triggiani was born in Naples in 1959 and earned his MD from the University of Naples Federico II in 1983. In 1990, he received his $\mathrm{PhD}$ in Cardiovascular Pathophysiology from the University of Rome. Dr. Triggiani was trained as a Postdoctoral Fellow in the Division of Allergy and Clinical Immunology at the Johns Hopkins University (Baltimore, Md., USA) from 1988 to 1991. He had been Assistant Professor and then Associate Professor of Medicine at the University of Naples Federico II from 1998 to 2011. Since 2012, he has been Associate Professor of Medicine at the University of Salerno (Italy) and Director of the Allergy and Clinical Immunology Unit at the University Hospital of Salerno.

Dr. Triggiani is President of the Italian Society of Allergy and Clinical Immunology (SIAIC) for the 2011-2014 mandate and a Member-at-Large of the Executive Committee of the European Academy of Allergy and Clinical Immunology (EAACI) for the 2011-2013 mandate.

Dr. Triggiani's main research interest is focused on the mechanisms involved in the activation of human cells in allergy and inflammation, such as mast cells, basophils and macrophages. His group contributed to the development of techniques to purify these cells from several human tissues and to explore their capacity to release proinflammatory mediators. His current research activity is aimed at investigating the biochemistry and functional activities of secreted phospholipases $\mathrm{A}_{2}$, an emerging class of inflammatory and immunoregulatory molecules involved in chronic inflammatory diseases of the lung.

Dr. Triggiani's clinical activities include outpatient and inpatient clinics for rare allergic diseases and clinical immunology, such as mastocytosis, hereditary angioedema, hypereosinophilic syndromes and systemic vasculitis. He is leading a reference center of the European Community Network for Mastocytosis (ECNM) and a national referral center for hereditary angioedema.

He is coauthor of more than 130 full papers on different topics in the field of basic and clinical immunology in peer-reviewed journals. 